\title{
Histiocitosis X pulmonar. Presentación de un caso y revisión de la literatura
}

\author{
Ma . C. ABELLÁN MARTÍNEZ, P. MÉNDEZ MARTÍNEZ, F. SÁNCHEZ GASCÓN, \\ J. HERNÁNDEZ MARTÍNEZ, T. SÁNCHEZ MONTÓN, E. ROMERO MAS*
}

Servicio de Neumología. *Servicio de Cirugía. Hospital General Universitario de Murcia. Servicio de Medicina Interna. Hospital Los Arcos. Murcia

\author{
PULMONARY HISTIOCYTOSIS X. A CASE REPORT AND LITERA - \\ TURE REVIEW
}

\begin{abstract}
RESUMEN
La histiocitosis $\mathrm{X}$ o histiocitosis de células de Langerhans es una enfermedad infrecuente, que consiste en la proliferación de células de Langerhans. Su causa es desconocida. Al diagnóstico se llega mediante el estudio de biopsia de la lesión por microscopía electrónica, detectándose los gránulos de Birbeck intracitoplasmáticos de las células de Langerhans, y/o mediante técnicas inmunohistoquímicas, que detecten la proteina $S_{100}$ y las células $C D_{1}$. También es diagnóstico un porcentaje mayor del $5 \%$ de células $\mathrm{CD}$, en el lavado broncoalveolar.

Presentamos el caso de una paciente de 16 años, que se manifestó como una lesión pulmonar con un patrón radiológico en panal de miel y una afectación ósea mandibular asintomática. Al diagnóstico se llegó mediante el estudio de la biopsia pulmonar por técnicas de detección de proteína $S_{100}$. Consideramos de interés este caso por la infrecuencia de esta enfermedad.
\end{abstract}

PALABRAS CLAVE: Histiocitosis. Células de Langerhans. Granuloma eosinófilo.

\begin{abstract}
Histiocytosis $X$ or Langerhans cell histiocytosis is an unfrequent disease, which consists on proliferation of Langerhans cells. The etio logy is unknown. Diagnosis is reached by electron microscope study of the biopsy, in which the Birbeck intracitoplasmatic granules of the Lan gerhans cells are found and/or by inmunohistochemistry procedures able to detect $S-100$ antigen and $C D_{1}$ cells. Diagnosis can also be reached with a bronchoalveolar lavage in which $C D_{1}$ cells will appear in a score higher than $5 \%$.

We present the case of a 16 year-old girl that first appeared with a pulmonar lesion with a honey comb X-ray pattern and unsintomatic mandibular bone affectation. Diagnosis was reached by biopsy study using S-100 antigen detection procedures. We consider this case an important one due to the unfrequency of this particular disease.
\end{abstract}

KEY WORDS: Histiocytosis. Langerhans cells. Eosinophilic granuloma.

Abellán Martínez $M^{a} C$, Méndez Martínez P, Sánchez Gascón F, Hernández Martínez J, Sánchez Montón T, Romero Mas E. Histiocitosis X pul monar. Presentacion de un caso y revision de la literatura. An Med Interna (Madrid) 2002; 19: 16-18.

\section{INTRODUCCIÓN}

La histiocitosis X o histiocitosis de células de Langerhans incluye enfermedades que difieren tanto en su clínica como en la edad de presentación, aunque comparten un sustrato morfológico común, la proliferación histiocítica. Estas enfermedades son el granuloma eosinófilo, la enfermedad de Letterer-Siwe y la enfermedad de Hand-Schüller-Christian. El granuloma eosinófilo afecta sobre todo a los adultos y puede ser focal o multifocal. La enfermedad de Hand-Schüller-Christian consiste en la triada de lesiones craneanas osteolíticas, diabetes insípida y exoftalmía. La enfermedad de Letterer-Siwe ocurre en lactantes y niños, presenta afección multiorgánica y su curso es fatal. Presentamos un caso de granuloma eosinófilo en una paciente de 16 años y realizamos una revisión de la literatura.

\section{CASO APORTADO}

Paciente de 16 años, que consultó por disnea de grandes esfuerzos y tos productiva de un año de evolución. Entre sus antecedentes personales refería la extirpación de adenopatías inguinales cuatro años antes, siendo al parecer de etiología benigna, pues no disponía del informe anatomopatológico. Apendicectomía en la infancia. No tuvo infecciones respiratorias de repetición en la infancia. No reseñaba viajes al extranjero ni contacto con animales. No tomaba drogas ni medicamentos. Era fumadora de 10 cigarrillos al día desde hacía cuatro años. Trabajaba en un almacén de pimientos, sin inhalación de productos tóxicos.

Contaba disnea de grandes esfuerzos desde hacía un año, acompañada de tos y expectoración, que inicialmente fué verdosa, convirtiéndose posteriormente en blanquecina. No presentaba dolor torácico, hemoptisis ni síndrome febril. Refería pérdida de peso no

Trabajo aceptado: 20 de Abril de 2000

Correspondencia: María del Carmen Abellán Martínez. C/ Almirante Churruca n ${ }^{\circ} 7,2^{\mathrm{a}}$ esc. $2^{\circ}$ A. 30007 Murcia 
cuantificada y prurito generalizado desde hacía un año, sin astenia, anorexia ni sudoración profusa. No tenía dolores óseos.

A la exploración se apreciaba una constitución leptosómica, con buena coloración e hidratación. Las constantes vitales estaban dentro de los límites normales. Se observaba acné facial. Se palpaban adenopatías laterocervicales, inguinales y axilares bilaterales de $0,5 \mathrm{~cm}$. de diámetro, móviles, rodaderas, no dolorosas, sin enrojecimiento cutáneo. No se apreciaba bocio. A la auscultación respiratoria sólo destacaba hipofonesis en campos medios pulmonares. El resto de la exploración era normal.

Las determinaciones analíticas, como hemograma, coagulación, bioquímica sérica, orina, proteinograma, velocidad de sedimentación globular, factor reumatoide, inmunoglobulinas y anticuerpos antinucleares fueron normales. El complemento sérico (C3) estaba por debajo de sus valores de referencia: $82,6 \mathrm{mg} / \mathrm{dl}$ (83-177). La gasometría arterial mostró: $\mathrm{pH} 7,43, \mathrm{P}_{\mathrm{a}} \mathrm{CO}_{2} 39 \mathrm{mmHg}, \mathrm{PaO}_{2} 108 \mathrm{mmHg}$, $\mathrm{HCO}_{3} 26 \mathrm{mmol} / \mathrm{l}$, saturación $98 \%$.

En la radiografía simple de tórax destacaba un patrón intersticial, con imágenes quísticas de pared delgada, que predominaba en campos medios pulmonares. La caja torácica, los hilios y la morfología cardiaca no mostraban alteraciones (Fig. 1). La TAC torácica evidenciaba un patrón difuso intersticial bilateral con áreas en panal de miel; en el mediastino no se apreciaban masas ni adenopatias. En una TAC craneal se observaban quistes en la mandibula. Se realizaron radiografías óseas de las extremidades que fueron normales. Las pruebas funcionales respiratorias mostraron los siguientes resultados: SVC: $77 \%$, FVC: $80 \%$, FEV1: $97 \%$, FEF 25-75\%: 68\%, TLC: 77\%, RV: $109 \%$, DSB: $57 \%$, VA: $82 \%$, D/VA: $68 \%$. Presentaba, por tanto, un patrón restrictivo leve con disminución moderada de la difusión. La microbiología del esputo y la serología (virus de inmunodeficiencia humana, virus de Epstein-Barr, Citomegalovirus, Chlamydia, Mycoplasma, Legio nella, Coxiella burnetti) fueron negativas. El Mantoux también fué negativo.

Se realizó una broncoscopia, no apreciándose alteraciones macroscópicas. La microbiología del aspirado bronquial no arrojó más información y la citología mostró signos de inflamación con escasos linfocitos, numerosos macrófagos hemosiderínicos y células gigantes multinucleadas. Los datos aportados por la biopsia transbronquial no fueron concluyentes.

Llegados a este punto y sin diagnóstico etiológico se decidió la realización de una biopsia pulmonar a cielo abierto. Durante la toracotomía, desde el punto de vista macroscópico, se observaba a nivel subpleural quistes de paredes finas de menos de $0,5 \mathrm{~cm}$ de diámetro. El estudio microscópico informó de lesiones difusas de

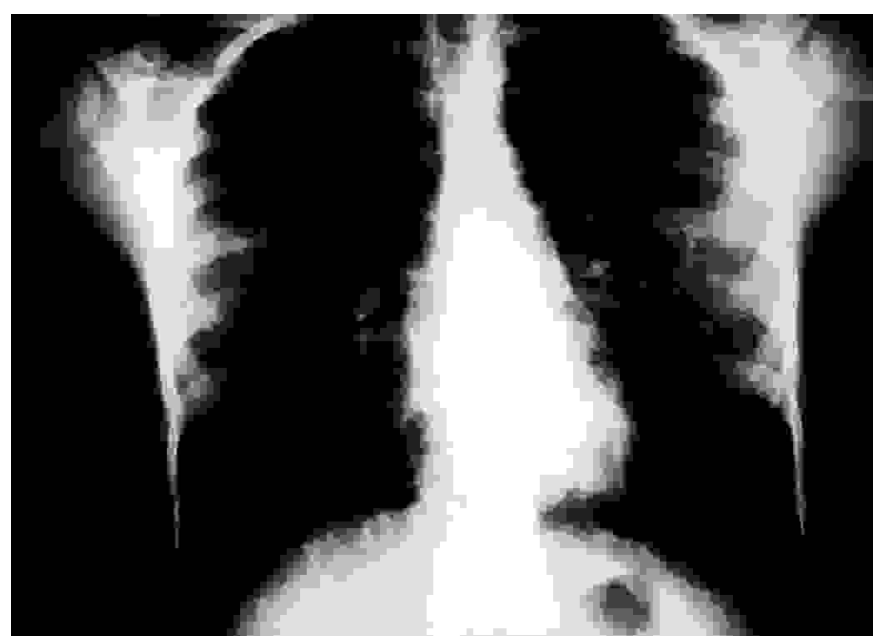

Fig. 1. Radiografía posteroanterior de tórax. Patrón instersticial bilateral, con imagenes quísticas de pared delgada, con predominio en la afectación de campos medios pulmonares. carácter parcheado, más prominentes debajo de la pleura,que consistieron en un infiltrado que se localizó en las paredes alveolares y alrededor de los vasos y bronquios, constituido por linfocitos, células plasmáticas y células histiocitarias de citoplasma acidófilo y núcleo hendido. Se observaban abundantes eosinófilos. En las luces alveolares aparecían numerosos macrófagos cargados de hemosiderina. Se apreciaba fibrosis con formación de cicatrices estrelladas, que distorsionaban el parénquima, con formación de grandes espacios aéreos rodeados de tejido fibrótico, configurando el cuadro de panal de miel.

\section{DISCUSIÓN}

La histiocitosis de células de Langerhans es una enfermedad infrecuente. La incidencia estimada es de 0,6 casos por año y por millón de niños menores de 15 años (1). El término histiocitosis de células de Langerhans incluye, entre otras enfermedades, al granuloma eosinófilo. Este afecta a adultos y compromete básicamente a pulmón. Es más frecuente en la raza blanca. Existe un pico de máxima incidencia entre los 20-40 años. La etiología es desconocida, aunque las últimas investigaciones apuntan a una disfunción del sistema inmune, bien por inmunodeficiencia primaria a nivel de fagocitos multinucleares o por alteración en el control de las células citotóxicas por los linfocitos $\mathrm{T}$ supresores. A partir del estudio de muestras de lavado broncoalveolar se ha observado la proliferación local y afluencia de monocitos sanguíneos, que parecen ser los responsables del aumento en macrófagos alveolares inmaduros, que son activos funcionalmente. Se liberan radicales libres y fibronectina que ocasionan lesión pulmonar y fibrosis pulmonar. Se ha pensado también en una proliferación neoplásica clonal de las células de Langerhans, aunque recientes estudios indican que la replicación de estas células tiene una mínima contribución al mantenimiento del granuloma (2). Se han valorado también como factores etiológicos a virus y factores genéticos. El $90 \%$ de los afectados son fumadores.

El granuloma eosinófilo afecta al sistema óseo en un 4$20 \%$ de los casos, aunque es el pulmón el principal órgano implicado. Los huesos más afectados son mandíbula, cráneo, costillas y fémur (3). Se aprecian imágenes osteolíticas bien delimitadas, que clínicamente pueden ser asintomáticas, como en este caso, u ocasionar dolor, tumefacción, impotencia funcional o fracturas patólogicas. Se ha relacionado esta enfermedad con la espondilitis anquilosante (4).

Desde el punto de vista anatomopatológico macroscópico, se distinguen en las fases iniciales múltiples nódulos, que con el paso del tiempo tienden a confluir, evolucionando a zonas de fibrosis y quistes de tamaño variable. El único dato que diferencia a esta enfermedad de la alveolitis fibrosante idiopática es que se afectan los campos pulmonares superiores.

Microscópicamente aparece un infiltrado celular en el intersticio pulmonar, alrededor de los bronquiolos pequeños y las arteriolas acompañantes, extendiéndose posteriormente al intersticio alveolar. El infiltrado está compuesto de reticulohistiocitos, sobre todo eosinófilos, y menos, neutrófilos, linfocitos, células plasmáticas y células gigantes multinucleadas. La parte central de la lesión se fibrosa, adquiriendo una forma estrellada, con un infiltrado periférico. Al progresar la enfermedad los focos fibrosos confluyen, apreciándose quistes y histiocitos. Los linfocitos del infiltrado son casi todos CD3, con predominio de los CD4 (5). La 
fibrosis no parece desempeñar un papel importante en la génesis de la insuficiencia respiratoria sino que son las lesiones destructivas las que llevan a la desaparición del lecho capilar alveolar, siendo ésta la causa de la disnea. Las cavidades del pulmón apanelado son de procedencia variada: desaparición de las paredes de división del alveolo, bronquiolos dilatados y granulomas cavitados (6). Al microscopio electrónico las células de la histiocitosis tienen microvellosidades de superficie diseminadas y el citoplasma contiene los gránulos de Birbeck o de Langerhans, que están formados por dos unidades de membrana paralelas y separadas por una banda delgada de material granular o estriado; a veces estos gránulos presentan una terminación en forma de raqueta de tenis.

En cuanto a la clínica, el $64 \%$ presenta síntomas y el resto se descubre en una radiografía de tórax de rutina. Los síntomas respiratorios aparecen en el $60 \%$ de los casos. Los más frecuentes son la tos seca y la disnea. El dolor torácico puede deberse a un neumotórax o a un dolor óseo. Pueden manifestar pérdida de peso, como le ocurrió a nuestra paciente, astenia y fiebre (30\% de los casos). Las linfadenopatías periféricas son infrecuentes en los adultos, presentándose, sin embargo, a menudo durante la infancia.

Se han descrito casos de afectación ganglionar exclusivamente (7). Ocurre neumotórax espontáneo en un $10 \%$ de los casos, pudiendo ser bilateral en ocasiones (8). Debe de valorarse cuidadosamente en estos casos la realización de pleurodesis bilateral ya que en algunos centros la existencia previa de ésta contraindica el trasplante (9). A la auscultación pueden escucharse crepitantes finos.

El estudio radiológico de tórax muestra una afectación difusa y simétrica bilateral, con predominio en campos medios y superiores, tal y como presentaba nuestra paciente. Inicialmente se aprecia un patrón nodular, con nódulos entre 1-10 mm, que evoluciona a un patrón reticulonodular, reticular grueso y finalmente a patrón en panal de miel, con quistes de pared delgada de menos de $1 \mathrm{~cm}$. Raramente aparece derrame pleural, adenopatí- as hiliares o mediastínicas, consolidación alveolar algodonosa con patrón en alas de mariposa o nódulos cavitados. El volumen pulmonar es normal en el $60 \%$ de los casos, con pérdida de volumen en el $9 \%$ e hiperinsuflación en el resto.

Respecto a las pruebas funcionales puede aparecer un patrón restrictivo, como el caso clínico expuesto, con disminución de VC, siendo el VR como los flujos espiratorios normales. También puede existir un patrón obstructivo, sobre todo en las fases avanzadas. La difusión suele estar alterada. Puede observarse hipoxemia con el ejercicio.

Para el diagnóstico se precisa una biopsia pulmonar o bien una muestra de lavado broncoalveolar (BAL), en el que se realiza un estudio por microscopía electrónica, identificando los cuerpos de Birbeck en las células de Langerhans, o bien, por el empleo de marcadores inmuno-histoquímicos, detectando la proteína $S_{100}$ o las células $C_{1}$ positivas (10). En el BAL hay un aumento en el recuento celular total, con sólo ligeros cambios en el contaje diferencial, siendo diagnóstico si aparecen más del $5 \%$ de células $\mathrm{CD}_{1}$ positivas (11). La ausencia de $\mathrm{CD}_{1}$ no descarta el diagnóstico, pues sólo aparecen en el 50-70\% de los casos, debido a la distribución parcheada de la enfermedad (12). Para confirmar el diagnóstico nosotros usamos la detección de la proteína $\mathrm{S}_{100}$ en una biopsia pulmonar.

Dado la frecuencia de remisiones espontáneas descritas, debe mantenerse en observación al paciente si éste está asintomático. Deberá abandonar el hábito tabáquico (13). Si está sintomático o la enfermedad progresa puede iniciarse tratamiento con corticoides durante un año a dosis de 0,5-1 mg/Kg/día de prednisona o dosis equivalentes de otros glucocorticoides. Si no hubiera respuesta puede recurrirse a inmunosupresores como el etopóxido (14), ciclosporina, metotrexate y vinblastina (1). En estadios muy evolucionados puede estar indicado el trasplante pulmonar, aunque se han descrito recidivas posteriores (15).

En cuanto al pronóstico de la histiocitosis de células de Langerhans, éste empeora en el caso de niños, enfermedad generalizada y patrón en panal de miel.

\section{Bibliografía}

1. Fernández Delgado R, Brugieres L. Enfermedades del sistema mononuclear fagocítico. Histiocitosis. Medicine 1997; 7: 2833-2837.

2. Brabencova E, Tazi A, Lorenzato M, Bonay M, Kambouchner M, Emile JF et al. Langerhans cells in Langerhans cell granulomatosis are not actively proliferating cells. Am J Pathol 1998; 152 (5): 1143-9.

3. Vandeurzen K, Delanote M, Verschakelen J, Sciot R, Decramer M. Pulmonary histiocytosis X diagnosed by bone biopsy. Report of a case. Acta Clin Belg 1994; 49: 99-103.

4. Alvarez-Sala R, Prados C, De Miguel E, García Talavera I, Muñoz J. Histiocitosis X y espondilitis anquilosante. ¿Patogenia común? . An Med Interna (Madrid) 1996; 13: 339-340.

5. Kulwiec EL, Linch DA, Aguayo SM, Schwarz MI, King TE. Imaging of pulmonary histiocytosis X. Radiographics 1992; 12: 515-526.

6. Tazi A, Bonay M, Grandsaigne M, Battesti JP, Hance AJ, Soler P. Surface phenotype of de Langerhans cells and lymphocytes in granulomatous lesions from patients with pulmonary histiocytosis X. Am Rev Respir Dis 1993; 147: 1531-1536.

7. Rovira E, Michavila J, Ferrando J, Belda A, Gonzalvo F, Redón J. Histiocitosis de células de Langerhans de presentación ganglionar. An Med Interna (Madrid) 1996; 13: 589-591.

8. Loire R, Brune J. Les lesions evoluees graves de l'histiocytose X pulmonai- re. A propos de 3 transplantations. Rev Mal Respir 1993; 10: 223-228.

9. Callebaut W, Demedts M, Verleden G. Pulmonary Langerhans' cell granulomatosis ( histiocytosis X ): clinical analysis of 8 cases. Acta Clin Belg 1998; 53(5): 337-43.

10. Auerswald U, Barth J, Magnussen H. Value of CD-1 positive cells in bronchoalveolar lavage fluid for the diagnosis of pulmonary histiocytosis X. Lung 1991; 169: 305-309.

11. Castella J, Ancoechea J, Llorente JL, Puzo C, Sanchís J, Sueiro A et al. Normativas SEPAR. Lavado Broncoalveolar. Arch. Bronconeumol 1997; 33: 515-526.

12. Von Essen S, West W, Sitorius M, Rennard SI. Complete resolution of roentgenographic changes in a patient with pulmonary histiocytosis $\mathrm{X}$. Chest 1990; 98: 765-767.

13. Smith PJ, Soues S. Multilevel therapeutic targeting by topoisomerase inhibitors. Br J Cancer 1994; 23 Suppl 1: 47-51.

14. Arico M, Colella R, Conter V, Indolfi P, Pession A, Santoro N et al. Cyclosporine therapy for refractory Langerhans cell histiocytosis. Med Pediatr Oncol 1995; 25: 12-16.

15. Gabbay E, Dark JH, Ashcroft T, Milne D, Gibson GJ, Healy M et al Recurrence of Langerhans' cell granulomatosis following lung transplantation. Thorax 1998; 53(4): 322-3. 